\title{
A AVAliação E O ERRO NO PROCEsSO de ENSINO- APRENDIZAGEM NA FORMAÇÃO INICIAL E CONTINUADA DE PROFESSORES DE MATEMÁTICA
}

\author{
EVALUATION AND ERROR IN THE TEACHING LEARNING PROCESS IN THE \\ INITIAL AND CONTINUING TRAINING OF MATHEMATIC TEACHERS
}

DOI: http://dx.doi.org/10.23926/RPD.2526-2149.2020.v5.n1.p544-562.id611

\section{Marcelo Orlando Sales Pessim \\ Mestrando em Educação \\ Matemática (PPGEM/UNIR) \\ pessim_opo@hotmail.com}

\section{Eliana Alves Pereira \\ Leite \\ Doutora em Educação \\ (UFSCar) \\ Professora do Departamento \\ de Matemática e Estatística e \\ do Programa de Pós- \\ Graduação em Educação \\ Matemática da Universidade \\ Federal de Rondônia \\ (DME/PPGEM/UNIR) \\ eliana.leite@unir.br}

Resumo: Teve-se por objetivo analisar como a avaliação e o erro no processo de ensino-aprendizagem têm sido abordados na formação inicial e continuada de professores de matemática. Metodologicamente a pesquisa é de abordagem qualitativa e de campo. Participaram 5 professores de matemática que atuam nos anos finais do Ensino Fundamental e Médio de escolas estaduais de Ouro Preto do Oeste/RO. Para tanto, utilizou-se questionário, entrevista semiestruturada e procedeu-se a análise documental de Projetos Pedagógicos do Curso (PPCs) de Licenciatura em Matemática da Universidade Federal de Rondônia (UNIR), Campus de Ji-Paraná. Verificou-se que somente 2 professores participaram de algum tipo de estudo sobre avaliação e erro no processo de ensino-aprendizagem na formação inicial, e 4 professores tiveram acesso à discussão da referida temática na formação continuada. Nos PPCs, dos ciclos de 2000-2005 e 2006-2016, não foram encontrados elementos que se referem ao erro, no entanto, no segundo PPC, identificou-se em um componente curricular, mais especificamente em uma unidade, a discussão sobre a avaliação como um dos conteúdos programáticos. Espera-se que os resultados propiciem reflexões sobre a importância de ser oportunizado ao professor de matemática conhecimento acerca da avaliação na formação inicial e continuada.

Palavras-chave: $\mathrm{O}$ erro; Ensino-aprendizagem; Formação inicial; Formação Continuada; Professor de matemática.

\begin{abstract}
This article's aim was to analyze how evaluation and error in the teaching-learning process has been addressed in the initial and continuing education of mathematics teachers. Methodologically the research has a qualitative and field approach. Five mathematics teachers who work in the final years of elementary and high school from state schools in Ouro Preto do Oeste/RO participated. For this purpose, a questionnaire, semistructured interview was used and the documental analysis of Pedagogical Projects of the Course (PPCs) of the Mathematics Degree at the Federal University of Rondônia (UNIR), Campus of Ji-Paraná was carried out. It was found that only two teachers participated in some type of study on evaluation and error in the teaching-learning process in the initial training, and four teachers had access to the discussion of that theme in continuing education. In the PPCs, from the 2000-2005 and 2006-2016 cycles, no elements were found that refer to the error, however, in the second PPC, the discussion of evaluation as a component was identified in a curricular component more specifically in a unit programmatic content. It is expected that the results will provide reflections on the importance of giving mathematics teacher knowledge about the assessment in initial and continuing education.
\end{abstract}

Keywords: The mistake; Teaching and learning; Initial formation; Continuing Education; Mathematics teacher. 


\section{INTRODUÇÃo}

A formação de professores tem se constituído em objeto de investigação de várias pesquisas no campo da Educação Matemática. Considera-se que a quantidade de estudos nessa temática tem se acentuado, sobretudo na última década, como uma forma, dentre outros motivos, de se produzir conhecimento acerca do tipo de formação que tem sido propiciada ao futuro professor de matemática, a fim de identificar as lacunas formativas desse profissional e buscar implementar ações e mudanças curriculares que minimizem ou superem tais lacunas.

Isso é importante na medida em que se pondera o fato de que a formação obtida na trajetória formativa do professor impacta sua prática profissional. Nesse sentido, quando se reflete sobre a necessidade de mudanças no âmbito escolar e, mais especificamente, acerca de como promover um ensino que propicie uma aprendizagem matemática significativa, um dos aspectos que devem ser considerados nesse debate é a formação do professor.

Sabe-se que a formação do professor é um processo contínuo e não linear (MIZUKAMI et al., 2010; PASSOS et al., 2006) e que, portanto, ocorre em diferentes momentos da trajetória do indivíduo (IMBERNÓN, 2011). Dentre os contextos formativos que integram esse percurso, destacam-se a formação inicial e a formação continuada. Sendo que o primeiro tipo de formação se caracteriza como o espaço em que se deve fornecer um repertório de conhecimentos profissionais a respeito da profissão docente, constituindo-se, desse modo, em uma referência para iniciar a carreira docente (LEITE, 2016). Por sua vez, a formação continuada possibilita abordar temas e aspectos que decorrem de demandas que emergem na profissão. Com isso, o docente tem a possibilidade de ampliar e reorganizar o repertório de conhecimentos, até então construído na formação inicial e acrescido com as experiências da prática, bem como de construir novos saberes.

Nesse cenário, acredita-se que um dos temas que têm sido silenciados na formação inicial e na formação continuada do professor de matemática é o conhecimento sobre a avaliação do processo de ensino-aprendizagem, uma vez que há poucas pesquisas que abordam essa temática. Além disso, a respeito da avaliação, vários aspectos podem ser investigados, dentre os quais chama-se a atenção para o erro no processo de ensino-aprendizagem da matemática, que se constitui, também, como uma temática pouco investigada. Destarte, entende-se que essa temática é fundamental no processo de formação do professor dessa área do conhecimento, visto que ele deverá não apenas saber identificar o erro dos alunos, mas saber, ademais, diferenciar os tipos, bem como intervir no erro para que o mesmo seja superado e que o aluno alcance a aprendizagem. 
Diante do exposto, é que, neste estudo, objetivou-se analisar como a avaliação e o erro no processo de ensino-aprendizagem têm sido abordados na formação inicial e continuada de professores de matemática. Sabe-se que esse objeto pode ser investigado sob a perspectiva curricular, no caso do Projeto Pedagógico do Curso de Licenciatura em Matemática; dos professores formadores (da formação inicial e continuada); e dos professores que vivenciaram esses tipos de formações, entre outros. Assim, no presente estudo, buscou-se compreender tal fenômeno sob a perspectiva dos professores de matemática que atuam na Educação Básica, e que, portanto, já vivenciaram a formação inicial e possuem experiências na formação continuada, bem como no PPC do curso de Licenciatura em Matemática, em que esses professores são egressos. Cabe destacar que esse estudo resulta de um Trabalho de Conclusão de Curso na Especialização em Educação Matemática.

\section{FORMAÇÃo do PROFESSOR de MATEMÁtica: EM FOCO A FORMAÇÃo INICIAL E A CONTINUADA}

A formação do professor é um processo complexo e, dessa forma, não se limita a um contexto de formação circunscrito em um recorte temporal (LEITE, 2016). Nesse viés, Pacheco e Flores (2000, p. 47) destacam que "aprender a ensinar implica um processo evolutivo, com fases e impactos distintos, em que o ponto de partida é a experiência adquirida enquanto aluno e o ponto de chegada é a experiência enquanto professor". Corroborando a ideia de que o processo formativo do professor pode começar com as experiências vivenciadas enquanto aluno da Educação Básica, Leite (2016, p. 32) elucida que "a aprendizagem docente é aquela que se tem a possibilidade de obter em diferentes momentos, até mesmo antes de se tornar professor". Partindo dessa compreensão, em função do objeto delimitado neste estudo, procurou-se discorrer sobre as potencialidades de dois contextos que integram essa trajetória de formação do professor, que se trata da formação inicial e a da formação continuada.

A formação inicial pode ser considerada como um momento "muito importante para a incorporação de uma cultura profissional, ou seja, para a aquisição de características essenciais do professor de matemática" (PEREZ, 1999, p. 272). Ainda de acordo com Leite (2016, p. 43):

\section{A formação inicial pode ser considerada como um espaço formal, que de maneira intencional visa sistematizar alguns dos conhecimentos profissionais e, portanto, necessários à prática docente, tais como: do currículo, da área específica, didático- pedagógico, avaliação, de como organizar e gerir uma sala de aula, entre outros.}

Esse espaço formal se caracteriza, segundo Mizukami (2008, p. 216), como um momento "em que processos de aprender a ensinar e aprender a ser professor começam a ser 
construídos de forma mais sistemática, fundamentada e contextualizada". Portanto, coaduna-se com o fato de que a formação inicial deve dotar o futuro docente "de uma bagagem sólida nos âmbitos científicos, cultural, contextual, psicopedagógico e pessoal que deve capacitar o futuro professor ou professora a assumir a tarefa educativa em toda sua complexidade" (IMBERNÓN, 2011, p. 68).

$\mathrm{O}$ ato de ensinar exige muito mais do que simplesmente transmitir conhecimentos, visto que é necessário ter compreensão aprofundada do que se ensina, saber ensinar de diferentes formas, considerando que há uma diversidade nas especificidades dos alunos, posteriormente, avaliar o que foi ensinado e, concomitantemente a isso, estar preparado para as demandas que podem emergir em sala de aula. Sendo assim, verifica-se que há uma diversidade de conhecimentos que devem ser propiciados na formação inicial. Ao se refletir especificamente sobre a formação do professor de matemática e sobre quais conhecimentos são necessários, Albuquerque et al. (2006, p. 14) elucidam as seguintes categorias de conhecimento:

conhecimento relativo à natureza da matemática; conhecimento relativo aos conteúdos matemáticos; conhecimento relativo aos objetivos curriculares; conhecimento relativo à forma de apresentar as ideias de modo a que sejam aprendidas pelos alunos; conhecimento relativo à forma como os alunos compreendem e aprendem os conteúdos matemáticos; conhecimento relativo à gestão da sala de aula.

Desse modo, fica claro que a formação inicial não deve privilegiar, na formação do futuro professor, apenas conhecimentos específicos de sua área, pois o processo de ensinoaprendizagem exige mais do que se ter conhecimento do conteúdo a ser ensinado. Nessa mesma direção, Serrazina (2012, p. 66) destaca que "não basta ao professor saber a matemática que ensina, mas tem também de saber como a ensinar e como avaliar as aprendizagens que daí resultam".

Assim, chama-se a atenção para o conhecimento sobre avaliação no processo de ensinoaprendizagem da matemática, uma vez que ela se configura em "uma tarefa complexa que não se resume à realização de provas e atribuição de notas. A mensuração apenas proporciona dados que devem ser submetidos a uma apreciação qualitativa" (LIBÂNEO, 2013, p. 216). Portanto, deve-se ter o entendimento de que a avaliação "é uma tarefa didática necessária e permanente do trabalho docente, que deve acompanhar passo a passo o processo de ensino e aprendizagem" (LIBÂNEO, 2013, p. 216). Para tanto, faz-se necessário ter uma compreensão sobre o que é, para quê e como avaliar, bem como os tipos de funções da avaliação no processo de ensinoaprendizagem da matemática. 
Considera-se que esse conhecimento deve ser oportunizado em uma perspectiva teórica e prática tanto na formação inicial quanto na continuada, uma vez que se entende, assim como Serrazina (2014, p. 1054), que a "a formação continuada deve contribuir para que os professores avancem no nível de compreensão das suas práticas”. Nesse sentido, Gatti e Barreto (2009, p. 221) salientam que "[...] os professores valorizam o potencial presente nas oportunidades de formação continuada, não apenas na perspectiva de desenvolvimento profissional, mas também com objetivos mais imediatos de melhoria de desempenho em sala de aula". De acordo com Modesto (2002, p. 12-13):

[...] a formação inicial sozinha não dá conta de toda a tarefa de formar os professores: é preciso cada vez mais se promover uma formação permanente que não termine com a formação inicial, nos cursos de licenciatura, mas que vá além disto, que prossiga ao longo do desenvolvimento profissional do professor, como formação continuada em serviço.

Partindo da ideia de Modesto (2002), embora se reconheça as potencialidades formativas dos cursos de licenciatura, percebe-se que esse contexto tem limitações e, por isso, não há condições de possibilitar a construção de todos os conhecimentos exigidos na profissão docente, visto que a sociedade está em constante mudança, e isso exige cada vez mais desse profissional. Nessa conjuntura é que se considera a formação continuada de suma importância para não apenas suprir as lacunas formativas decorrentes da licenciatura, mas também para tratar de aspectos que surgem das demandas profissionais.

No entanto, Mizukami et al. (2010, p. 26-27) salientam que "ao longo dos últimos anos, nas discussões sobre formação continuada, vem-se questionando a oferta, pela universidade e por outras agências, de cursos de curta duração (30-180 horas) como meio efetivo para a alteração de práticas pedagógicas". Haja vista que para essa mesma autora, "esses cursos, quando muito, fornecem informações que, algumas vezes, alteram apenas o discurso dos professores e pouco contribuem para uma mudança efetiva". Nessa mesma direção, Curi e Pires (2008, p. 183) destacam que "[...] muitas vezes o tempo de formação é insuficiente, tanto para que o professor se aproprie de conhecimentos que não domina, como para que ele ganhe confiança e disposição para realizar mudança em sua prática”.

Em virtude disso, é que se considera que os estudos promovidos pela formação continuada têm que ir ao encontro das demandas do docente, sendo que essas demandas vão variar a partir do tempo de experiência do profissional iniciante e experiente. Além do mais, vale salientar que essas formações não devem ocorrer de forma aligeirada, bem como não devem privilegiar a dimensão prática do conhecimento em detrimento do teórico e, por fim, não 
se deve priorizar somente o como ensinar, mas se faz necessário abordar também outros conhecimentos que são inerentes ao processo de ensino-aprendizagem da matemática, como, por exemplo, o ato de avaliar. Destarte, considera-se que a formação continuada se constitui em um momento importante na trajetória de formação do professor, pois ela possibilita ampliar o repertório de conhecimentos adquiridos na formação inicial, reorganizá-lo e, até mesmo, construir novos aprendizados.

\section{AVALIAÇÃo E O ERRO NO PROCESSO DE ENSINO-APRENDIZAGEM}

A avaliação é fundamental na prática pedagógica, tendo em vista que, "por meio dela, os resultados vão sendo obtidos no decorrer do trabalho conjunto do professor e dos alunos são comparados com os objetivos propostos, a fim de constatar progressos, dificuldades e reorientar o trabalho nas correções necessárias" (LIBÂNEO, 2013, p. 216). Isso ocorre por considerar que "a avaliação da aprendizagem do aluno está diretamente ligada à avaliação do próprio trabalho docente. Ao avaliar o que o aluno conseguiu aprender, o professor está avaliando o que ele próprio conseguiu ensinar" (HAIDT, 2006, p. 288). Desse modo, "a avaliação é uma reflexão sobre o nível de qualidade do trabalho escolar tanto do professor como dos alunos" (LIBÂNEO, 2013, p. 216).

Com isso, destaca-se que a avaliação vai muito além da função de quantificar o que foi aprendido pelo aluno, visto que ela se apresenta como um processo contínuo e sistemático; funcional; integral e orientador (HAIDT, 2006). Para tanto, a avaliação possui funções bem circunscritas, que, segundo Libâneo (2013), seriam: pedagógico-didáticas, diagnóstica e de controle. Por sua vez, para Haidt (2006), tem-se a função diagnóstica, formativa e somativa. Assim como há outros autores que categorizam outros tipos de funções que se aproximam das que foram mencionadas.

A discussão apresentada acerca de alguns elementos sobre a avaliação tem a finalidade de explicitar sobre a complexidade e abrangência imbricada no ato de avaliar, corroborando o fato de que se fazem necessários estudos e debates sobre a avaliação no âmbito da formação inicial e continuada. Sendo que, na conjuntura desse processo, é necessário considerar, também, o conhecimento em relação ao erro do aluno.

Ao refletir sobre o erro em uma perspectiva mais abrangente, que, portanto, extrapola o contexto da educação, verifica-se que, no decorrer da "história das diferentes Ciências, especialmente na área de humanas e exatas, é possível verificar que o conhecimento não se caracteriza como algo pronto e acabado, mas em algo que é construído e, portanto, é passível 
de sofrer modificações, de ser reformulado e até mesmo de ser reconstruído" (PESSIM, 2015, p. 16).

Nessa direção, Bachelard (1996, apud PESSIM, 2016, p.16) destaca que:

O erro na história das Ciências tem um lugar privilegiado, uma vez que a Ciência se constitui em um espaço de produção de novos conhecimentos. O erro possibilita ao pesquisador rever e pensar a respeito de um problema, de qualquer natureza, em que de início parecia ter se obtido a resposta.

No entanto, sabe-se que, de uma forma geral, em diferentes culturas, o erro recebe uma conotação negativa, sobretudo na educação, em que errar se constitui quase como um sinônimo de incapacidade e fracasso. Para Luckesi (1999, p. 48):

A visão culposa do erro, na prática escolar, tem conduzido ao uso permanente do castigo como forma de correção e direção da aprendizagem, tomando avaliação como suporte da decisão. Todavia uma visão sadia do erro possibilita sua utilização de forma construtiva.

Essa perspectiva construtiva não é possibilitada, dentre outros motivos, pelo fato de que "a escola concebe o erro como uma falha, como algo a ser substituído, sem nenhuma reflexão prévia" (TANUS, 2008, p. 55). Destarte, é preciso considerar que o erro fornece “[...] pistas significativas dos múltiplos processos que atravessam a construção de conhecimentos, indícios que permitem ver além do imediatamente perceptível" (ESTEBAN, 2001, p. 27). Para que o docente possa assumir uma perspectiva construtiva do erro no processo de ensinoaprendizagem, é preciso considerar duas questões, sendo que:

A primeira coisa que devemos examinar é a própria noção de que erro é inequivocamente um indício de fracasso. A segunda questão intrigante é que, curiosamente, o fracasso é sempre o fracasso do aluno. O que gostaria de demonstrar é que a constatação de um erro não nos indica, de imediato, que não houve aprendizagem, tampouco nos sugere inequivocamente fracasso, seja da aprendizagem, seja do ensino (AQUINO, 1997, p. 12).

Nessa direção, tais elementos possibilitam compreender que:

O erro pode ser utilizado como uma estratégia inovadora para aproximar a teoria e a prática, para passar de um enfoque de resultados para um de processos, de uma pedagogia do êxito para uma didática do erro, de ensino de conteúdos para aprendizagem de processos. Em suma, que uma adequada conceitualização e utilização do erro no ensino possa tornar-se uma estratégia a serviço da inovação educativa (TORRE, 2007, p. 10).

Deste modo, a escola é o ambiente em que o aluno tem a oportunidade de errar e tornar o seu erro um caminho para potencializar a aprendizagem, fazendo dele um elemento importante para transpor as dificuldades. No entanto, isso não ocorre de forma espontânea, uma vez que, para que o erro se constitua em uma ponte para a aprendizagem, é necessária a 
intervenção do professor. Abrahão (2004, p. 37) explicita cinco estratégias que podem ser utilizadas pelo professor na intervenção do erro do aluno.

Observação - Observando-a e fazendo observar problema, questionando-se: "onde foi que eu errei? Por quê?; reconstituição (atual e retroativa) - descrever ações que está realizando ou já realizou: "como eu cheguei a essa compreensão"; antecipação imaginar o resultado de uma ação, fazer estimativas, planejar: "o que vai acontecer se fizermos desta forma?”; comparação/verificação/contraposição - decidir sobre um ponto de vista a partir de outras respostas (do grupo): “como resolvestes esta questão desta maneira? Como conseguistes essa resposta? Por que acha que a sua resposta está diferente da resposta do teu colega?"; explicação/justificativa - responder ao "por quê" e "como você sabe": "O que achas que a questão pediu?".

Concomitante a essas estratégias, faz-se necessário propiciar "um tratamento diferenciado com o erro do aluno, de modo que este não seja apenas classificado como resposta errada, produto final a ser banido, punido, mas, transformado, superado, considerando o processo de reflexão do aluno como forma de avançar no conhecimento" (TANUS, 2008, p. 56). Assim, para que o erro seja compreendido pelo docente como parte do processo de ensinoaprendizagem, é essencial que ele tenha um conhecimento abrangente sobre a avaliação. Isso implica dizer que não basta apenas conhecer o conceito, mas também conhecer sobre a evolução histórica acerca dos diferentes tipos de concepções de avaliação, assim como qual dessas concepções tem sido considerada, na atualidade, como a mais adequada no âmbito da educação. Além do mais, faz-se necessário saber diferenciar os tipos de funções atribuídos à avaliação e os tipos de erros (conceitual, atitudinal e procedimental) cometidos pelo aluno para que, posteriormente, o docente possa definir a melhor forma de intervenção.

Acrescenta-se ainda a necessidade de se ter o entendimento sobre os diferentes instrumentos que podem ser utilizados para avaliar a aprendizagem. Para tanto, ressalta-se que, para que o professor tenha compreensão dessas dimensões do conhecimento que se referem à avaliação, faz-se necessário promover estudos, debates e experiências na formação inicial e continuada.

\section{Metodologia}

Metodologicamente, a pesquisa é de abordagem qualitativa, sendo que Silva e Menezes (2001, p. 20) consideram que nessa abordagem:

\footnotetext{
há uma relação dinâmica entre o mundo real e o sujeito, isto é, um vínculo indissociável entre o mundo objetivo e a subjetividade do sujeito que não pode ser traduzido em números. A interpretação dos fenômenos e a atribuição de significados são básicas no processo de pesquisa qualitativa. Não requer o uso de métodos e técnicas estatísticas. $\mathrm{O}$ ambiente natural é a fonte direta para coleta de dados e o pesquisador é o instrumento-chave. É descritiva. Os pesquisadores tendem a analisar seus dados indutivamente. $\mathrm{O}$ processo e seu significado são os focos principais de abordagem.
} 
No que diz respeito à modalidade da pesquisa, destaca-se que ela é de campo. De acordo com Fiorentini e Lorenzato (2012, p. 71), essa modalidade é aquela em que "a coleta de dados é realizada diretamente no local em que o problema ou fenômeno acontece e pode dar-se por amostragem, entrevista, observação participante, pesquisa-ação, aplicação de questionário, teste, entre outros".

Em virtude disso, a pesquisa de campo ocorreu em escolas estaduais da cidade de Ouro Preto do Oeste, com 5 professores de matemática que atuam nos anos finais do Ensino Fundamental e Médio. Neste estudo, os sujeitos foram identificados com nomes fictícios, sendo: Margarete, José, Davi, Tomé e Isaac.

Para a produção de dados, procedeu-se a análise de documento, aplicação de questionário e entrevista semiestruturada com os 5 professores de matemática. O questionário possui 9 questões e trata de um dos instrumentos mais utilizados na produção de dados, ademais apresenta questionamentos de cunhos objetivo (fechado) e subjetivo (aberto), ou ainda misto (fechado e aberto) (FIORENTINI; LORENZATO, 2012). Por sua vez, a entrevista semiestruturada apresenta 10 questionamentos e pode ser caracterizada como uma técnica "em que o investigador se apresenta frente ao investigado e lhe formula perguntas com o objetivo de obtenção de dados que lhe interessam à investigação" (GIL, 1999, p. 117).

Relativamente à análise documental, Gil (2009, p. 166) salienta que "são considerados documentos não apenas os escritos utilizados para esclarecer determinada coisa, mas qualquer objeto que possa contribuir para a investigação de determinado fato ou fenômeno". Portanto, fez-se análise de PPCs do curso de Licenciatura em Matemática da Universidade Federal de Rondônia (UNIR) do campus de Ji-Paraná, uma vez que os professores participantes da pesquisa são egressos do referido curso.

O curso de Licenciatura em Matemática atende, além de Ji-Paraná, acadêmicos de municípios circunvizinhos, a saber: "Cacoal, Rolim de Moura, Ariquemes, Mirante da Serra, Presidente Médici, Ouro Preto e Jaru” (UNIR, 2005, p. 4). Quanto ao surgimento do referido curso, destaca-se que era ofertado "o curso de Ciências com habilitação em Matemática reconhecido pelo MEC no ano de 1987 e que funcionou até o ano de 1991” (UNIR, 2005, p. 4). Outrossim, somente em 1992, começou-se a ofertar o curso de Licenciatura em Matemática, que teve seu reconhecimento pelo MEC em 24 de agosto de 1999 através da Portaria ${ }^{\circ} 1.280$ (UNIR, 2005). Cabe ressaltar que, desde a criação do referido curso de Licenciatura em Matemática, já tiveram 4 PPCs, sendo o último aprovado pela Resolução no 491/CONSEA, de 
14 de junho de 2017. Em face disso, existiram currículos diferentes nos períodos de 1992-1999; 2000-2005; 2006-2016; 2017 à atualidade) (ALBUQUERQUE, 2014).

Foram analisados os PPCs dos ciclos de 2000-2005 e de 2006-2016. A escolha somente desses documentos, excluindo-se, portanto, os de 2017 à atualidade, refere-se ao fato de que os professores participantes da pesquisa cursaram os 3 primeiros currículos, não sendo encontrado somente o PPC que diz respeito ao ciclo de 1992-1999. Os referidos documentos foram obtidos no site do Departamento de Matemática e Estatística (DME).

Nesses documentos, a procura textual acerca do fenômeno que se investigou se deu por meio da ferramenta de busca do PDF, cujas palavras-chave utilizadas foram: avaliação, avaliar, erro e prova. Em relação à apresentação dos dados, teve-se, quanto aos decorrentes do questionário, a indicação da sigla Quest seguida pelo número da questão (Quest/01) e, de forma semelhante, os dados referentes à entrevista foram destacados como (Entrev/01). No que diz respeito aos dados do PPC, utilizou-se a sigla UNIR/PPC com a indicação do ciclo correspondente e a página. Os trechos dos dados evidenciados de forma indireta foram apenas seguidos com a identificação do instrumento no corpo do parágrafo correspondente. No entanto, os trechos dos dados explicitados na íntegra foram apresentados entre aspas, em itálico, sendo colocados no corpo do parágrafo.

Para interpretação e discussão dos dados, recorreu-se a algumas estratégias de análise de conteúdo, visto que, segundo Lakatos e Marconi (2017, p. 309), a abordagem da análise de conteúdo ocorre em três etapas: "a pré-análise (seleção do material e definição dos procedimentos a serem seguidos), a exploração do material, o tratamento dos dados e interpretação". O termo análise de conteúdo designa, para Bardin (2011, p. 47), "um conjunto de técnicas de análise das comunicações visando a obter por procedimentos sistemáticos e objetivos de descrição do conteúdo das mensagens". Com isso, entende-se que foi possível obter elementos dos professores de matemática quanto à avaliação e ao erro no processo de ensino-aprendizagem da matemática no âmbito da formação inicial e continuada.

\section{Resultados}

Nesse momento de apresentação, interpretação e discussão dos dados, buscou-se abordar, primeiramente, elementos que se referem à formação inicial dos professores de matemática para, posteriormente, discorrer sobre a formação continuada. Assim, em relação à formação inicial, salienta-se o fato de que os 5 professores são egressos do curso de Licenciatura em Matemática da UNIR, campus de Ji-Paraná, ao passo que Davi concluiu o curso em 1998, 
Margarete e José em 2004, Isaac em 2008 e Tomé em 2009 (Quest/2a). Com isso, verifica-se que o período de formação varia do final da década de 1990 à primeira década do século XXI. Destaca-se, ainda, que os 5 professores são efetivos da rede pública do estado de Rondônia, cuja experiência profissional docente varia de 3 a 26 anos (Quest/03).

\subsection{AVALIAÇÃo E O ERRO NO PROCESSO DE ENSINO-APRENDIZAGEM dA MATEMÁTICA NA FORMAÇÃO INICIAL DO PROFESSOR DE MATEMÁTICA}

Ao identificar que os 5 professores participantes da pesquisa são egressos da UNIR, chama-se a atenção para a importância e a responsabilidade da referida Instituição de Ensino Superior (IES) na formação de professores de matemática na região central do estado. Nesse cenário, evidencia-se que, embora os 5 professores sejam egressos da UNIR, somente Tomé e Margarete apresentam indícios de terem participado de estudos na formação inicial que se referem à avaliação e ao erro no ensino-aprendizagem da matemática.

Tomé explicitou: "Na faculdade já se comentou, mas a gente vê na teoria é diferente do que a gente faz na prática. Na teoria a gente aborda assunto, conhece essas facetas que estão comentadas sobre avaliação. Mas na realidade às vezes por questão de tempo, não temos oportunidade de estar abordando esse assunto constantemente” (Entrev/01). Nessa mesma direção, Margarete afirmou: “Eu vejo na área de matemática uma falha muito grande, começa na nossa formação. A nossa formação acadêmica ela é de teoria a maior parte dela [...]. Quando partimos para a sala de aula temos que tirar esse desnível entre o procedimento que é a sala de aula e a teoria" (Entrev/05).

Diante disso, verifica-se que há indícios de que a formação obtida por Tomé e Margarete, na licenciatura, acerca da avaliação e do erro no processo de ensino-aprendizagem da matemática se limitou a uma dimensão teórica, distanciando-se, portanto, de um conhecimento que se aproxima do que efetivamente é necessário na prática profissional. Além disso, Tomé destacou que considera "o assunto importante na formação docente, uma vez que vem sempre somar conhecimentos, e que vai possibilitar até à gente mudar as práticas que às vezes a gente vem executando na sala de aula e nortear caminhos diferenciados para conseguir os objetivos" (Entrev/02).

Isso remete ao fato de que, para que haja uma mudança de prática, é necessário ter uma formação que oportunize, de forma suficiente, a apropriação do conhecimento, visto que essa segurança é que ocasionará a disposição do professor em rever a própria prática (CURI; PIRES, 2008). 
Não obstante, considerou-se preocupante o fato de que somente 2 dos professores afirmaram ter participado de estudos acerca do erro no processo de ensino-aprendizagem da matemática no curso de licenciatura. Além do mais, há indícios de que tais estudos aconteceram de forma incipiente, não contribuindo efetivamente na prática desses docentes em sala de aula. Acerca dos PPCs, verificou-se que não há nenhuma discussão sobre a avaliação e o erro nesse processo.

Isso chama atenção na medida em que se entende que, para se romper uma visão culposa do erro no espaço escolar (LUCKESI, 1999), de falha (TANUS, 2008) ou, até mesmo, de fracasso (AQUINO, 1997), constitui-se como fundamental possibilitar aos futuros professores de matemática estudos, debates e práticas a fim de que se tenha condições de não apenas mudar a concepção desse profissional, mas propiciar um repertório de conhecimento que aborde o quê, como, quando e o porquê avaliar.

No PPC que se refere ao período de 2000-2005, não foi encontrado nenhum aspecto que esteja relacionado à avaliação ou em específico sobre o erro no processo de ensinoaprendizagem de matemática. Conjecturava-se que houvesse alguma discussão no componente curricular de Didática (80 horas). Contudo, na relação de conteúdos programáticos, havia somente as seguintes unidades, com os respectivos conteúdos: "UNIDADE I - A Didática: conceito e objetivos UNIDADE II - Tendências Pedagógicas UNIDADE III - Planejamento de ensino" (UNIR/PPC, 2000-2005, p.103).

No entanto, no PPC de 2006-2016, currículo em que Margarete e Tomé obtiveram formação, foram identificados elementos que se referem à avaliação em uma perspectiva abrangente. Isso consta no componente curricular Didática Geral, ofertado no quarto período, que possui uma carga horária de 40 horas, mais especificamente na Unidade III do conteúdo programático ao abordar: "Planejamento do Ensino e Ciclo Docente: competências e/ou objetivos, conteúdos, metodologias de ensino-aprendizagem e avaliação e Educação Matemática" (UNIR/PPC, 2006-2016, p. 61). Embora esteja presente a temática avaliação no currículo do curso, acredita-se que os estudos podem ter ocorrido de forma limitada, uma vez que tiveram apenas 40 horas para trabalhar 4 unidades que tratam de diferentes aspectos com relação ao campo da Didática, às tendências pedagógicas e ao planejamento.

Além do mais, percebe-se que a discussão sobre avaliação foi abordada apenas como uma etapa ou parte do planejamento e que, assim, não consta uma discussão ampla sobre a avaliação e em específico sobre o erro no processo de ensino-aprendizagem da matemática. Nesse sentido, tem-se o entendimento de que, antes de serem oportunizadas as diferentes etapas 
do planejamento, particularmente da avaliação, faz-se necessário que o acadêmico tenha um conhecimento aprofundado sobre este assunto. De modo que, nesse bojo, inserem-se elementos sobre as concepções de avaliação, as funções (HAIDT, 2006; LIBÂNEO, 2013), os tipos de instrumentos, bem como acerca de como identificar e intervir no erro do aluno no processo de ensino-aprendizagem de matemática. Haja vista que, quando se aborda sobre o erro do aluno, há várias estratégias que não se referem somente a como diagnosticar o erro, mas também a como intervir de forma construtiva (ABRAHÃO, 2004; TORRE, 2007) para que se obtenha a aprendizagem.

No referido documento, também foi identificado a seguinte orientação para licenciando estagiário: "a avaliação diz respeito ao conteúdo construído pelos alunos (não comportamento do aluno), cuja aferição é preciso ser feita com diversos instrumentos e indicadores e critérios colocados com clareza para os alunos e conforme a legislação em vigor na escola" (UNIR/PPC, 2006-2016, p. 130). Consta, ainda, na ficha avaliativa do licenciando estagiário, como um dos critérios que norteia a avaliação do professor, que faz o acompanhamento do acadêmico na escola, o seguinte: "utiliza diversos instrumentos para avaliar a aprendizagem do conteúdo e faz isto de forma continuada" (UNIR/PPC, 2006-2016, p. 129). Por fim, dentre as competências e habilidades necessárias ao licenciado listadas no referido documento, consta a de: "avaliar seu trabalho de ensino, a aprendizagem dos futuros alunos e a execução do projeto pedagógico da escola" (UNIR/PPC, 2006-2016, p. 10).

Os elementos supracitados chamam a atenção, na medida em que se tem uma exigência posta nos estágios, em que o curso não possibilita condições efetivas para tal, cita-se como exemplo o fato de que o licenciando deve utilizar diferentes instrumentos na avaliação. Pois, dentre os diferentes conhecimentos necessários à docência (ALBUQUERQUE et al.,2006), é fundamental saber como avaliar as aprendizagens (SERRAZINA, 2012).

Desse modo, no decorrer da interpretação, foi possível identificar que, dos 5 professores, somente 2 (Tomé e Margarete) afirmaram ter tido a oportunidade de participar de algum modo de estudos sobre avaliação e o erro no processo de ensino-aprendizagem no contexto do curso de Licenciatura em Matemática. Contudo, ao se buscar no currículo do referido curso, não foi identificado nenhum aspecto referente ao erro no processo de ensino-aprendizagem da matemática, mas somente discussões que tratam sobre a avaliação em uma perspectiva genérica. Isso leva a conjecturar que, embora tal discussão não constasse efetivamente no PPC, os professores formadores podem ter abordado em algum momento no curso. 
Salienta-se, a partir dessa conjuntura, que, ainda que se tenha o entendimento de que a formação inicial tenha suas limitações e, portanto, não tem condições de cumprir sozinha a tarefa de formar um professor (MODESTO, 2002), faz-se necessário não perder de vista a função social e profissional desse espaço formativo, que é de promover uma cultura profissional (PEREZ, 1999), assim como uma bagagem sólida de conhecimentos de diferentes âmbitos, a fim de que esse futuro professor possa assumir a tarefa educativa em toda a sua complexidade (IMBERNÓN, 2011).

\subsection{AVALIAÇÃo E O ERRO NO PROCESSO DE ENSINO-APRENDIZAGEM dA MATEMÁTICA NA FORMAÇÃO CONTINUADA DO PROFESSOR DE MATEMÁTICA}

A formação continuada deve contribuir no sentido de possibilitar aos professores condições de avançarem no nível de compreensão de suas práticas profissionais (SERRAZINA, 2014). Desse modo, buscou-se verificar, também, se a formação continuada vivenciada pelos professores tem, de alguma forma, cumprido seu papel formativo no que tange à temática avaliação e ao erro no processo de ensino-aprendizagem da matemática. Essa formação pode ocorrer em diferentes contextos formativos, que vão desde cursos de Pós-Graduação, de cursos de curta ou longa duração, promovidos pelas secretarias, até mesmo ciclo de estudos e debates no próprio espaço escolar.

Assim, foi possível perceber que, dos 5 professores de matemática, 4 cursaram PósGraduação lato sensu, a saber: Davi, Metodologia do Ensino Superior; Margarete, Educação Matemática; Isaac e Tomé, em Didática e Metodologia do Ensino Superior (Quest/2b). No entanto, somente Margarete citou a Pós-Graduação como espaço em que foram propiciadas discussões acerca do erro do aluno. Uma vez que salientou: "[...] a gente trabalhou algumas questões relacionadas de como reverter esse erro ou identificar o que o aluno sabe ou não sabe. A partir desses erros deles, então eu trabalhei na minha Pós-Graduação" (Entrev/01). Cabendo destacar que a professora Margarete também afirmou que teve contato com discussões sobre o erro há “muito tempo, no início da minha docência”" (Quest/04). Acredita-se que o fato de que somente a referida docente tenha tido acesso a estudos dessa natureza na especialização esteja relacionado ao tipo de Pós-Graduação que ela cursou, que se refere à Educação Matemática.

Os demais professores (Isaac, José e Davi) participaram de estudos em outros espaços de formação continuada, a saber: na escola, oficinas e no Programa Pacto Nacional pelo Fortalecimento do Ensino Médio. Desse modo, somente Tomé não teve a oportunidade de 
participar de nenhuma discussão ou estudo sobre o erro do aluno no âmbito da formação continuada. Tomé destacou que foram abordados outros assuntos na formação continuada, mas que ainda não tinha tido a "oportunidade de discutir o assunto sobre o critério de avaliação. Eu não tive essa oportunidade de estudar especificamente sobre isso sobre avaliação. Mas na realidade às vezes por questão de tempos, não temos oportunidade de estar abordando esse assunto constantemente" (Entrev/01).

O espaço escolar foi mencionado pelo professor José, sendo que o referido docente disse que, na escola: "Sempre a gente está discutindo sobre esse assunto, às vezes mesmo não sendo uma reunião específica, mas quando estão os professores de matemática trocamos essas ideias. Discutimos a forma como o processo é conduzido e a maioria dos professores de matemática" (Entrev/01). O docente apresenta indícios de que alguns elementos que concernem à avaliação têm se constituído como objeto de diálogo entre os demais colegas da profissão. Isso é importante na medida em que cada professor tem a sua forma própria de conduzir não apenas o ensino, mas também a avaliação. Nesse sentido, conforme Esteban (2001), é importante que o professor conceba o erro como algo que fornece elementos de como o aluno está construindo o conhecimento.

No questionário, o professor Davi não relata ter participado de discussões sobre o erro na escola, mas, ao realizar a entrevista, o docente sinalizou positivamente, destacando que, nesse contexto, tem-se falado "sobre a forma do currículo da grade, a questão de quantidade de aula e de situações que envolvem o processo de ensino e aprendizagem, partindo da quantidade de aula da grade curricular até a forma de aplicação de aula [...] " (Entrev/01). No excerto, é possível verificar que o docente apresenta indícios de que a discussão acerca do erro no processo de ensino-aprendizagem da matemática se refere a outros aspectos que podem interferir na forma de avaliar.

Quanto ao Programa Pacto, Isaac destacou: "a gente discute todos os temas que envolvem a questão da aprendizagem do aluno e seus componentes. Com certeza, nós sabemos que é importantíssimo para o entendimento do profissional em relação aos alunos" (Entrev/01). Além disso, o docente salienta ter tido contato com discussões relacionadas a essa temática em "oficinas de matemática e encontros de formação continuada" (Quest/04).

Através dos dados obtidos, verifica-se que, de forma geral, os docentes tiveram mais acesso a discussões sobre a avaliação e o erro no processo de ensino-aprendizagem da matemática na formação continuada do que propriamente na formação inicial. No entanto, há indícios de que o repertório construído não se configura como suficiente para atender as 
demandas profissionais dos professores. Assim, mostra-se em conformidade com Mizukami et al. (2010) sobre a urgência de se ter cursos que alterem efetivamente a prática pedagógica dos professores e não apenas que forneçam informações de alterar apenas seus discursos.

A partir disso, pode-se conjecturar que se faz necessário oportunizar, na formação inicial, bem como na continuada, uma variedade de experiências que contemplem tanto a dimensão teórica quanto a prática da avaliação no processo de ensino-aprendizagem da matemática.

\section{CONSIDERAÇões FinAIS}

Neste estudo, objetivou-se analisar como a avaliação e o erro no processo de ensinoaprendizagem têm sido abordados na formação inicial e continuada de professores de matemática. Foi possível verificar que, na formação inicial, sob a perspectiva de 2 professores, isso ocorreu de maneira estritamente teórica. Com base nos PPCs, concernentes aos ciclos de 2000-2005 e 2006-2016, não foram identificados aspectos que se referem propriamente ao erro, todavia, no segundo PPC, em uma unidade, consta a avaliação como um dos conteúdos programáticos. A partir desse cenário, infere-se que nenhum ou poucos estudos não se constituem como suficientes para que o futuro professor construa um conhecimento amplo acerca da avaliação, que envolve, portanto, todas as dimensões (concepções, funções, instrumentos, como identificar e intervir no erro do aluno, entre outros).

Há elementos que evidenciam que os professores tiveram mais acesso à discussão sobre o erro e à avaliação no âmbito da formação continuada. Contudo, salienta-se que a forma e o que tem sido propiciado tem se constituído como limitado mediante as demandas profissionais dos docentes. Para tanto, considera-se que, para realização de formação continuada, promovida pelas Secretarias de Educação e pela própria escola, faz-se necessário conhecer quais as necessidades formativas dos professores e sistematizar um estudo/curso que não privilegie apenas a dimensão teórica da temática abordada.

Assim, espera-se que os resultados deste estudo possibilitem reflexões sobre a necessidade de se oportunizar o conhecimento sobre a avaliação no processo de ensinoaprendizagem tanto no âmbito da formação inicial do professor de matemática quanto na formação continuada.

\section{REFERÊNCIAS}

ABRAHÃO, Maria Helena Menna Barreto. A avaliação e o erro construtivo libertador: Uma teoria-prática includente em educação. Porto Alegre: EDIPUCRS, 2004. 
ALBUQUERQUE, Carlos.; VELOSO, Eduardo.; ROCHA, Isabel.; SANTOS, Leonor.; SERRAZINA, Lurdes.; NÁPOLES, Suzana. A matemática na formação inicial de professores. 1. ed. Lisboa: APM e SEMSPCE, 2006.

ALBUQUERQUE, Marlos Gomes Da formação polivalente ao movimento da Educação Matemática: uma trajetória histórica da formação de professores de matemática da Universidade Federal de Rondônia em Ji-Paraná (1988 - 2012). 276f. Tese (Doutorado em Educação em Ciências e Matemática) - Rede Amazônica de Educação em Ciências e Matemática (REAMEC), Universidade Federal de Mato Grosso, Cuiabá/MT, 2014. Disponível em:

https://www1.ufmt.br/ufmt/unidade/userfiles/publicacoes/c9b36615a212fde23a72ee64357f6a cf.pdf. Acesso em: 11 ago. 2019.

AQUINO, Júlio Groppa. Erro e fracasso na escola: alternativas teóricas e práticas. São Paulo: Summus, 1997.

BARDIN, Laurence. Análise de conteúdo. São Paulo: Edições 70, 2011.

CURI, Edda.; PIRES, Célia Maria Carolino. Pesquisas sobre a Formação do Professor que Ensina Matemática por Grupos de Pesquisa de Instituições Paulistanas. Educação Matemática Pesquisa, São Paulo, PUC/SP, 2008, n. 10, p. 151-189, 2008.

ESTEBAN, Maria Teresa. A avaliação no cotidiano escolar. 3. ed. Rio de Janeiro: DP\&A, 2001.

FIORENTINI, Dario.; LORENZATO, Sérgio. Investigação em Educação Matemática: percursos teóricos e metodológicos. 3. ed. Campinas: Autores Associados, 2012.

GATTI, Bernadete Angelina.; BARRETO, Elba Siqueira de Sá. Professores do Brasil: impasses e desafios. Brasília: UNESCO, 2009.

GIL, Antônio Carlos. Didática do ensino superior. 1. ed. 4. reimpressão. São Paulo: Atlas, 2009.

GIL, Antônio Carlos. Métodos e técnicas de pesquisa social. 5. ed. São Paulo: Atlas, 1999.

HAIDT, Regina Celia Cazaux. Curso de Didática Geral. 7. ed. São Paulo: Ática, 2006. (Série Educação).

IMBERNÓN, Francisco. Formação Docente e Profissional: formar-se para a mudança e a incerteza. 9. ed. São Paulo: Cortez, 2011.

LAKATOS, Eva Maria.; MARCONI, Mariana de Andrade. Metodologia científica. 7. ed. São Paulo: Atlas, 2017.

LEITE, Eliana Alves Pereira. Formação inicial e base de conhecimento para o ensino de matemática na perspectiva de professores iniciantes da Educação Básica. 269f. Tese (Doutorado em Educação), Universidade Federal de São Carlos, São Carlos/SP, 2016. Disponível em: https://repositorio.ufscar.br/bitstream/handle/ufscar/8107/TeseEAPL.pdf?sequence=1\&isAllo wed=y. Acesso em: 11 ago. 2019. 
LIBÂNEO, José Carlos. Didática. 2. ed. São Paulo: Cortez, 2013.

LUCKESI, Cipriano Carlos. Avaliação da aprendizagem: estudos e proposições. 9. Ed. São Paulo: Cortez, 1999.

MIZUKAMI, Maria da Graça Nicoletti. Aprendizagem da docência: conhecimento específico, contextos e práticas pedagógicas. In: NACARATO, Adair. Mendes. A formação do professor que ensina matemática perspectivas e pesquisas. Belo Horizonte: Autêntica, 2008. p. 213-231.

MIZUKAMI, Maria da Graça Nicoletti.; REALI, Aline Maria de Medeiros Rodrigues.; REYES, Claudia Raimundo.; MARTUCCI, Elizabeth Márcia.; LIMA, Emília Freitas de.; TANCREDI, Regina. Maria Simões Puccinelli.; MELLO, Roseli Rodrigues de. Escola e aprendizagem da docência: processos de investigação e formação. 2. ed. São Carlos: EDUFSCar, 2010.

MODESTO, Marco Antonio. Formação continuada de professores de matemática: compreendendo perspectivas, buscando caminhos. 190f. Dissertação de Mestrado em Educação, Faculdade de Ciências da Universidade Estadual Paulista (UNESP), Bauru/SP, 2002. Disponível em:

https://repositorio.unesp.br/bitstream/handle/11449/90905/modesto_ma_me_bauru.pdf?seque $\underline{\text { nce }=1}$. Acesso em: 11 ago. 2019

PACHECO, José Augusto.; FLORES, Maria Assunção. Formação e avaliação de professores. Porto: Porto, 2000.

PASSOS, Cármen Lúcia Brancaglion.; NACARATO, Adair Mendes.; FIORENTINI, Dario.; MISKULIN, Rosana Giaretta Sguerra.; GRANDO, Regina Célia.; GAMA, Renata Prenstteter.; MEGID, Maria Auxiliadora Bueno Andrade.; FREITAS, Maria Tereza Menezes.; MELO, Marisol Vieira de. Desenvolvimento profissional do professor que ensina matemática: uma meta-análise de estudos brasileiros. Revista Quadrante, Lisboa, v. 15, n. 1 e 2, p. 193-219, 2006. Disponível em: http://www.apm.pt/portal/quadrante.php. Acesso em: 11 ago. 2019.

PEREZ, Geraldo. Formação de professores de matemática sob a perspectiva do desenvolvimento profissional. In: BICUDO, Maria Aparecida Viggiani. Pesquisa em Educação Matemática: Concepções e Perspectivas. São Paulo: Editora Unesp, 1999. p. 263282.

PESSIM, Marcelo Orlando Sales. Concepção de Professores sobre o erro no processo de ensino-aprendizagem de Matemática em escolas públicas de Ouro Preto do Oeste/RO. 2015. 88f. Trabalho de Conclusão do Curso (graduação) - Universidade Federal de Rondônia, Ji-Paraná, 2015.

SERRAZINA, Maria de Lurdes Marquês. Conhecimento matemático para ensinar: papel da planificação e da reflexão na formação de professores. Revista Eletrônica de Educação, São Carlos, v. 6, n. 1, p. 266-283, mai. 2012. Disponível em:

http://www.reveduc.ufscar.br/index.php/reveduc. Acesso em: 11 ago. 2019. 
SERRAZINA, Maria de Lurdes Marquês. O professor que ensina matemática e a sua formação: uma experiência em Portugal. Educação \& Realidade, Porto Alegre, v. 39, n. 4, p. 1051-1069, out/dez. 2014. Disponível em:

https://seer.ufrgs.br/educacaoerealidade/article/view/45902. Acesso em: 10 ago. 2019.

SILVA, Edna Lúcia.; MENEZES, Estera Muszkat. Metodologia da pesquisa e elaboração de dissertação. 3. ed. Laboratório de Ensino a Distância da UFSC. Florianópolis: UFSC, 2001.

TANUS, Vera Lúcia Fernandes Aragão. O tratamento dado ao erro no processo de ensinoaprendizagem da Matemática, por professores do Ensino Fundamental: encontro e desencontros entre concepções e prática. Dissertação de Mestrado. Programa de PósGraduação em Educação, Universidade Federal de Mato Grosso/Cuiabá, 2008. Disponível em:

http://www.dominiopublico.gov.br/pesquisa/DetalheObraForm.do? select_action=\&co_obra=1 $\underline{23058}$ Acesso em: 02 set. 2019.

TORRE, Saturnino de La. Aprender com os erros: o erro como estratégia de mudança. Tradução Ernani Rosa. Porto Alegre: Artmed, 2007.

UNIVERSIDADE FEDERAL DE RONDÔNIA. Projeto Político Pedagógico do Curso de Licenciatura Plena em Matemática. Departamento de Ciências Exatas e da Natureza (DCEN), Ji-Paraná, 2000. Disponível em: http://www.dmejp.unir.br/uploads/96470485/arquivos/2000_Ementas_Licenciatura_em_M atem_tica_1407726555.pdf Acesso em: 02 set. 2019.

UNIVERSIDADE FEDERAL DE RONDÔNIA. Projeto Político Pedagógico do Curso de Licenciatura Plena em Matemática. Departamento de Ciências Exatas e da Natureza (DCEN), Ji-Paraná, 2005. Disponível em: http://www.dmejp.unir.br/uploads/96470485/arquivos/Projeto_pedagogico_matematica_2006 299615223.pdf. Acesso em: 11 ago. 2019.

Recebido em: 20 de janeiro de 2020.

Aprovado em: 29 de abril de 2020. 